Fr. Leybold: Beschreibung von vier neuen Vogelarten. 401

\title{
Beschreibung von vier neuen Vogelarten aus der Argentinischen Provinz Mendoza.
}

Von

\section{Friedrich Lejbold.}

Ich habe auch in diesem Sommer wieder eine Expedition für naturwissenschaftliche Sammlungen nach Mendoza über die Cordillera hinüber gesandt und hat dieselbe ausser den höchst eigenthümlichen von Chilenischer Fauna und Flora gänzlich verscbiedenen, jedoch schon beschriebenen Repräsentanten beider Reiche, folgende vier Species mitgebracht, welche sich als noch unbekannt erwiesen. - Herr Louis Landböck, der Conservator des hiesigen Museums, hatte die Gefälljgkeit, die Diagnosen zu machen. - Jene Gegenden sind noch fast unuatersucht uud werden noch lange neue höchst interessante Beute darbieten.

1. Synallaxis crassirostris nov. sp. Landböck.

Artkennzeichen: Schnabel stark; Unterseite weiss; rothbrauner Kinn甘leck; rostfarbige Unterdeckfedern des Schwanzes und der Flügel.

\section{Beschreibung:}

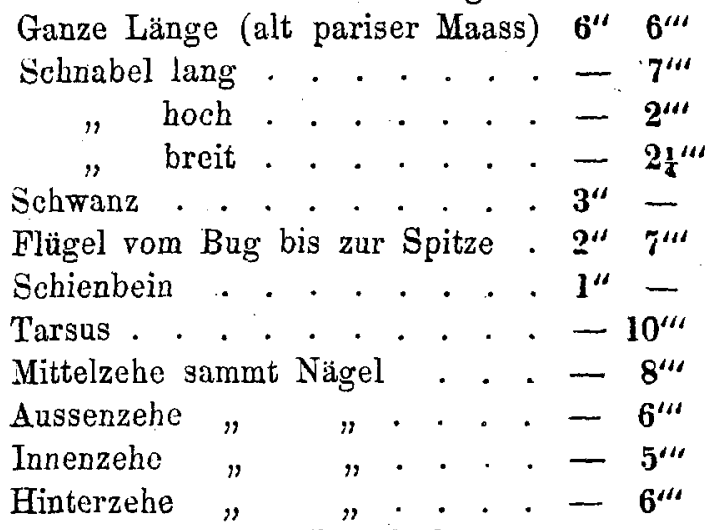

Schnabel stark von den Nasenlöchern nach vorne comprimirt, mit deutlich abgesetzter Firste, Innenränder schwach eingezogen, gerade; Oberschnabel hornschwarz; Unterschnabel an der Wurzel hornweisslich, die Vorderhälfte wie der Oberschnabel; der Fuss ist stark, deutlich geschildert, die Nïgel kurz, stark gebogen, mit scharfen Spitzen, horngrau. Die Oberseite ist röthlichgrau, auf dem Scheitel und Bürzel mehr'ins Rothgraue, an den Halseiten in trübes Aschgrau übergehend, die Oberschwanzdeckfedern sind 
rein rostroth, die kleinern Oberflügeldeckfedern haben dieselbe Farbe, aber matter, die grössern Deckfedern sind bräunlich, bis braunschwarz; erstere mit fahlen Kanten, letztere mit breiter rostrother Einfassung der Aussenfahnen, wodurch auf den Scbwungfedern zweiter'Ordnung ein rother Spiegel entsteht; ausserdem ist bei fast sämmtlichen Schwungfedern von der 7. der ersten Ordnung an gerechnet die Wurzelhälfte durchaus rostroth, welche Farbe auch die Unterflügeldeckfedern haben; die 2. Schwungfeder ist die kürzeste, die $\mathbf{4}$ folgenden sind beinahe gleichlang. Der Schwanz ist stufig und es überragt die längste Mittelfeder die äusserste kürzeste um $\mathbf{1}^{\prime}$. 'Die $\mathbf{2}$ Mittelfedern sind einfarbig braunschwarz, die äusserste einfarbig rostroth; bei der 2. von áussen ist die Wurzel und Aussenfahne, bei der 3. die Wurzel und BasalHälfte der Aussenfahne, bei den 2 folgenden immer weniger roth, aber die Enden immer schwarz. Der Zügel ist weiss, ein ziemlich grosser Fleck aber und hinterhalb des Auges, sowie Wangen und Ohren grau, die ganze Unterseite weiss, mit Ausnahme eines rostrothen, weissgekanteten Kinnfleckes, der rostfarbigen Bauchseiten und dergleichen Unterschwanzdeckfedern.

Männchen und Weibchen sind gleich gefärbt und der junge Vogel weicht nur durch den lichtgelben Kinnfleck von dem Alten ab.

In Hecken halbwegs ron den Häusern von "Melocoton" gegen den Fluss "Tunuyan"; sitzen ganz zahm im Gebüsch und schreien. 15. Januar.

2. Myiarchus fasciatus n. sp. Landböck.

Artkennzeichen. Zwei weisse Binden über die Flügel, am rothen Schwanze eine schwarze Endbinde.

\section{Beschreibung:}

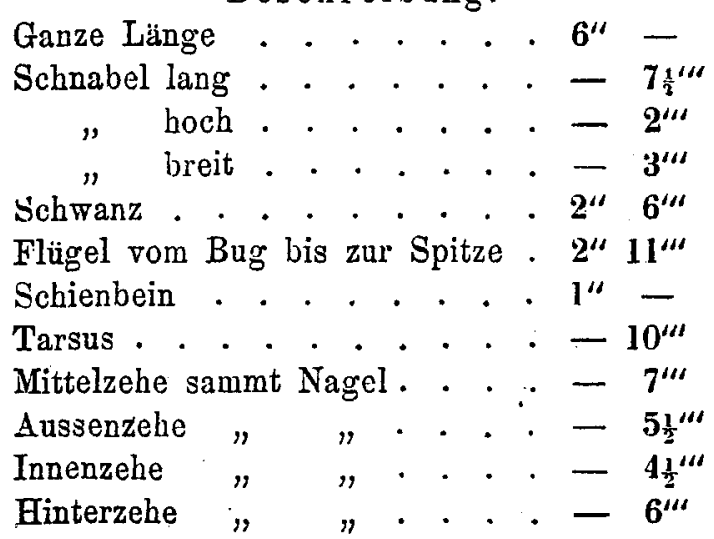


Vogelarten aus der Argentinischen Provinz Mendoza. 403

Schnabel gerade, die Spitze des Oberschnabels in ein feines Häkchen übergebogen, vor demselben ein schwacher Ausschnitt, Schnabelränder eingezogen, Firste deutlich abgesetzt, der Schnabel im Ganzen deprimirt, hornschwarz, an der Wurzel des Unterschnabels leicht horngrau. Am Schnabelwinkel ziemlich lange steife Bartborsten; das Nasenloch an der Basis mit weisslichen Federn bedeckt, vorne offen. Iris braun. Der Fuss mittelmässig stark, gebogene Klauen, glänzendschwarz. Die Schwungfedern sind schmal, fast lanzettartig zugespitzt, die J. die kürzeste; die 3. und 4. die längsten und gleichlang; Schwanz unbedeutend abgerundet.

Altes Männchen: Stirn und Gesicht hell, graubräunlich mit lichtrothfarbigen Schmitzen; Haube dunkelbraun; mit verlängerten etras zugespitzten Federn eine aufrichtbare Holle bildend; Hinterhals und Rücken graubraun; Unterrücken und Bürzel rostroth, walche Farbe auch der Schwanz hat, jedoch mit Ausnahme der schwarzen Spitzen, welche bei der äussersten Feder $6^{\prime \prime \prime}$ beträgt und sich bis zur mittelsten gradatim auf 1 " 6 " vergrössert. Die Flügel sind schwarz, die Schwungfedern leicht gerändert, was besonders bei den 3 letzten auffallend ist. Die Spitzen sämmtlicher grossen Deckfedern sind breit weiss, so dass dadurch zwei lichte Querbinden auf den Flügeln gebildet werden; diese weissen Spitzen, sowie die Ränder der grössern von den kleinsten Deckfedern sind etwas roströthlich iiberflogen. Die Innenfahne der Schwungfedern ist auf der Basalbälfte und die Unterflügeldeckfedern ganz licht rostroth. - Die Unterseite ist schmutzig lehmgelblich, an den Seiten der Kehle schwärzlich geschuppt, die Brust rothgelb, an den Seiten in die graubraune Rückenfarbe übergehend und die Unterschwanzdeckfedern leicht rostgelb. Das alte Weibchen hat im Wesentlichen dieselbe Zeichnung und Färbung, statt des rostgelblichen Ueberflugs dominirt aber mehr das Weisse. Die Scheitelfedern sind schwarz, rostroth gerändert, der Rücken mehr erdbraun, auf den Flügeln sind dieselben lichten Binden vorhanden aber schmäler und reinweiss; das Rostroth auf der Unterseite des Filügels ist sehr blass; im schwanze sind die 2 mittelsten Federn ganz schwarz, die übrigen haben nur breite schwarze Spitzen und mit Ausnahme der äussersten schwarze Aussenfahnen, die äusserste hat eine fast weisse Aussenfahne. Die Unterseite ist schmutzigweiss, an der Kehle mit grauen Längsflecken, welche sich auf der Brust verbreitern, so dass die Seiten derselben fast einfarbig 
dunkelbraungrau, die Mitte aber grau und weissgefleckt erscheint. Bauchseiten graubraun, Unterschwanzdeckfedern weiss.

Findet sich auf Gebüsch sitzend in den Cienegas (Sumpfgegenden) de Vistaflor östlich von den Häusern vor Melocoton. 13. Januar.

3. Sporophila rufirostris n. sp. Landböck.

Artkennzeichen. Schnahel, Füsse und After roth. Beschreibung:

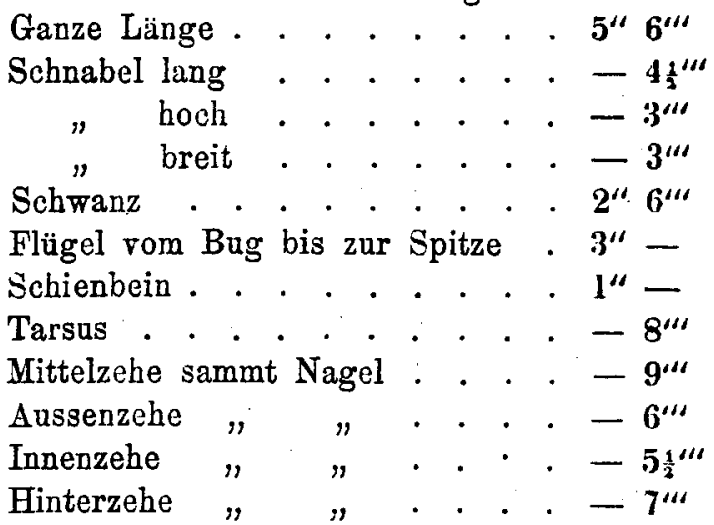

Schnabel stark aufgetrieben, gewölbt, Oberschnabel auffallend gebogen, an den Rändern etwas eingezogen, lackroth, an der Wurzel des Unterschnabels weisslich; die Nasenlöcher liegen vertieft, sind klein, rund und offen; Füsse verhältnissmässig stark, Zehen dünn; die Nägel lang, fein, stalk gebogen, horngrau, der Fuss fleischroth, Iris ...., die Hauptfarbe des ganzen Gefieders ist mit folgenden Ausnahmen ein dunkles Bleigrau: die Kopffedern haben einen schwarzen Mittelstrich, welcher auf die Rückenfedern so stark ausgedehnt ist, dass schwarze lanzettförmige Flecken entstehen; ausser diesem sind die Rückenfedern noch fein weiss gerändert. Schwung- und Schwanzfedern sind schwarz mit weisslichen Rändern, die Flügel und Schwanzdeckfedern breit grau eingefasst. Auf dem Hinterbauch und After geht das ohnediess hellere Grau der Unterseite in schmutziges Weiss über. Fin Theil der After- und sämmtliche Unterschwanzdeckfedern sind lebhaff rostroth.

Sehr scheu und selten bei der Guardia östlich rom Portillopasse; sitzen auf Steinen umher und singen untertags einen ganz allerliebsten Gesang, bübscher denn irgend ein anderer Vogel der chilenischen und der Mendozafauna. 7. Januar 1865. 
Vogelarten aus der Argentinischen Provinz Mendoza. 405

4. Phrygilus ornatus n. sp. Landböck.

Artkennzeichen: Zwei breite weisse und eine schwarze Querbinde über die Flügel und weissgefleckter Schwanz.

Beschreibung:

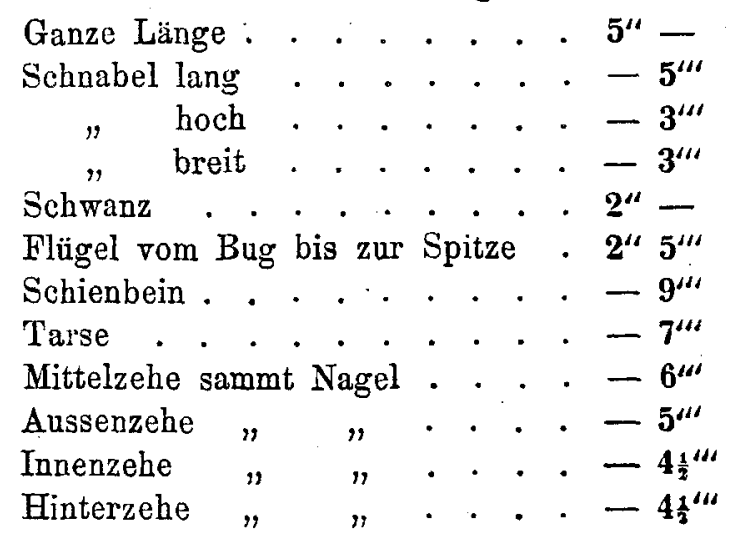

Schnabel verhältnissmässig schwach, sanft gebogen, an den Rändern ziemlich stark eingezogen, vor- und seitwärts zusammengedrückt, dunkel hornblau, auf der Unterseite des Schnabels mit lichtem Fleck. Irịs braun; Fuss ziemlich stark mit kurzen starkgebogenen Nägeln, graubraun. Stirne, Scheitel, Genick, Oberhals und Wangen dunkel aschgrau, auf dem Kopfe mit kleinen schwarzen Mittelfleckchen. - Von den Nasenlöchern beginnend, zieht sich über dem Auge hin bis zum Genicke eine rostweissliche Binde; der Oberrücken ist lebbaft chocoladenbraun, Unterrücken mit Bürzel graubraun, Oberschwanzdeckfedern aschgrau mit hellrostgelblichen Spitzchen. Der Schwanz ist abgerundet. Die äusserste Steuerfeder ist auf der Aussenfahne fast ganz, auf der Innenfahne an der Spitzenhälfte reinweiss; die 2. hat auf der Innenfahne einen $9^{\prime \prime \prime}$ langen weissen Spitzenfleck; die übrigen Schwanzfedern mit Ausnahme der zwei mittelsten, welche ganz schwarz sind, haben ähnliche kleinere weisse Spitzenflecke. - Die Schulter- und kleinen Flïgeldeckfedern sind düster grau mit bräunlichem Anfluge; die zwei Reihen der grossen Deckfedern sind schwarz, die kleinern mit breiter weisser Einfassung, die grössern mit weissen Aussenfahnen, wodurch zwei auffallende weisse Binden entstehen, welche eine schwarze beiderseits begränzen; die Schwungfedern sind schwarz, mit feinen graulichen Rändern; Unterflügeldeckfedern weiss, am Vorderrand des Flügels gelblich. Ganze Unterseite 
schön kastanienbraun, am Kinn fast weiss und am Bauche, After und Unterschwanzdeckfedern rostgelb.

In der trockenen wasserleeren Pampa auf dem Wege ron der Guardia des Portillo-Passes gegen die Häuser von Melocoton scheu und rasch durchs Gebüsch schlüpfend. 8. Januar 186.5.

Santiago de Chile, 27. März 1865.

\section{Ueber \\ neue oder weniger bekannte exotische Vögel. \\ Vóm \\ Herausgober.}

Climacocercus zonothorax n. sp.

Die geographische Verbreitung des im östlichen Südamerika, namentlich in ganz Brasilien, ziemlich häufigen Sparvizs ruficollis Vieill. erstreckt sich auf dem amerikanischen Continente nicht so weit nördlich als bisher angenommen zu werden scheint. Es wird diese Art vielmehr vorzugsweise als brasilisch zu betrachten sein; denn der in den Küstenstrichen von Neu-Granada vorkommende Vogel wird mindestens als constante climatische Abart betrachtet werden müssen. Im Laufe der Zeit hatte ich Gelegenheit, mehrere von Porto-Cabello kommende, vollständig übereinstimmende Exemplare zu untersuchen, auch besitzt eins derselben das Berliner Museum und ein anderes befindet sich in der Heine'schen Sammlưgg zu Halberstadt. Es sind alte, anscheinend vollständig auṣgefärbte Exemplare. Die jüngeren Kleider kenne ich nicht.

Im Vergleiche zum alten Vogel von $C$. ruficollis ist diese Art in allen Körperverhältnissen etwas grösser und daher auch mit grösserem Schnabel. Das Rothbraun der Oberseite ist dunkler und an der Unterseite ist nur die Kehle ähnlich, aber etwas heller gefärbt. Die übrige Unterseite, mit Einschluss der Brust, ist auf weisslichem Grunde schwarz quergewellt. Diese dunkle Querzeichnung ist viel breiter als bei ruficollis und erscheint daher schwärzer, mithin die Unterseite überhaupt dunkler gefärbt als bei dem brasilischen Vogel.

Letzteren nannte Temminck wegen der von der Kehle abwärts sich über die Brust erstreckenden rothbraunen Färbung ganz bezeichnend xanthothorax. Diese Brustfärbung ist aber bei unserm Vogel nicht vorhanden, sondern durch die über die ganze 